\title{
Doxycycline Malaria Prophylaxis Impact on Risk of Travelers' Diarrhea among International Travelers
}

\author{
Kathryn Lago, ${ }^{1,2 *}$ Kalyani Telu, ${ }^{3,4}$ David Tribble, ${ }^{3}$ Anuradha Ganesan, ${ }^{3,4,5}$ Anjali Kunz, ${ }^{6}$ Charla Geist, ${ }^{7}$ Jamie Fraser, ${ }^{3,4}$ \\ Indrani Mitra, ${ }^{3,4}$ Tahaniyat Lalani, ${ }^{3,4,8}$ and Heather C. Yun ${ }^{1,2}$ for the Infectious Disease Clinical Research Program \\ TravMil Study Group
}

${ }^{1}$ Brooke Army Medical Center, Fort Sam Houston, Texas; ${ }^{2}$ Uniformed Services University of the Health Sciences, Bethesda, Maryland; ${ }^{3}$ Infectious Disease Clinical Research Program, Department of Preventive Medicine and Biostatistics, Uniformed Services University of the Health Sciences, Bethesda, Maryland; ${ }^{4}$ The Henry M. Jackson Foundation for the Advancement of Military Medicine, Inc., Bethesda, Maryland; ${ }^{5}$ Walter Reed National Military Medical Center, Bethesda, Maryland; ${ }^{6}$ Madigan Army Medical Center, Tacoma, Washington; ${ }^{7}$ Landstuhl Regional Medical Center, Landstuhl, Germany; ${ }^{8}$ Naval Medical Center, Portsmouth, Virginia

\begin{abstract}
International travelers are frequently at risk for travelers' diarrhea (TD) and malaria. Doxycycline was one of the earliest antibiotics shown to have efficacy in TD prevention. With increasing resistance and recommendations against antibiotic chemoprophylaxis, doxycycline fell out of use. We evaluated TD incidence and risk factors in a prospective cohort of travelers, specifically in regard to malaria prophylaxis. Travelers' diarrhea was defined as $\geq 3$ loose stools in 24 hours or two loose stools in 24 hours associated with other gastrointestinal symptoms. The Poisson regression model with robust error variance was used to estimate the RR of TD. Three thousand two hundred twenty-seven trips were enrolled: $62.1 \%$ of participants were male, with a median age of 39 years (interquartile range [IQR] 27,59) and a median travel duration of 19 days (IQR 12,49); $17.4 \%$ developed TD; $32 \%$ traveled to Africa, $40 \%$ to Asia, and $27 \%$ to the Caribbean and Latin America; and 20\% took doxycycline for malaria chemoprophylaxis, $50 \%$ took other antimalarials, and $30 \%$ took none. Decreased RR of TD was associated with doxycycline (RR $0.62[0.47-0.82], P<0.01)$ and military travel (RR 0.57 [0.47-0.70], $P<0.01)$. Increased risk of TD was associated with female gender (RR 1.28 [1.09-1.50], $P<$ 0.01), hotel accommodations (RR 1.30 [1.10-1.53], $P<0.01)$, travel to tropical South America (RR 1.34 [1.09-1.64], $P<$ $0.01)$, and duration of travel (RR 1.00 [1.00-1.01], $P<0.01$ ). The use of doxycycline for malaria prophylaxis is associated with lower TD risk, suggesting increasing bacterial enteropathogen susceptibility similar to previous observations. Doxycycline selection for antimalarial chemoprophylaxis may provide additional traveler benefit in infection prevention.
\end{abstract}

\section{INTRODUCTION}

Travelers' diarrhea (TD) is the most common illness experienced by international travelers and can occur during travel to any part of the world. ${ }^{1,2}$ Travel destination heavily influences the incidence rate of TD. Travelers to developing countries have an incidence rate of $20 \%$ per 2-week stay, whereas those traveling to low-risk areas (United States, Western Europe, and Australia) have a $<8 \%$ per 2-week stay TD incidence. ${ }^{3}$ Although mortality from TD is low, TD can cause significant incapacitation both during and after travel. ${ }^{3}$ Thirty percent of travelers to high-risk areas can become incapacitated from TD and may not be able to participate in planned activities for up to 24 hours. ${ }^{3}$ In addition, the evidence increasingly suggests a link between TD and the development of irritable bowel syndrome (IBS). ${ }^{4}$

With the high incidence of TD among international travelers and its associated morbidity, it is important to counsel travelers on TD prevention measures. Currently, TD prevention strategies are focused on food and water restrictions and chemoprophylaxis. ${ }^{5,6}$ Currently, there is no antibiotic with an approved indication for TD prophylaxis. In the previous two decades, rifaximin, a nonabsorbable antibiotic with a favorable safety profile, has demonstrated moderate efficacy in TD prevention. ${ }^{5}$ In the 1970 s-1980s, doxycycline was commonly prescribed as TD prophylaxis. Multiple studies showed that taking daily doxycycline during travel significantly reduced the incidence of TD. ${ }^{7,8}$ By the mid-1980s, doxycycline resistance

\footnotetext{
*Address correspondence to Kathryn Lago, Infectious Disease Service, Brooke Army Medical Center, 3551 Roger Brooke Dr., Joint Base San Antonio, Fort Sam Houston, TX78234. E-mail: kathryn.j.lago.mil@ mail.mil
}

began to emerge, especially in enterotoxigenic Escherichia coli (ETEC).$^{9-11}$ Therefore, the 1985 National Institute of Health Consensus Statement on TD recommended early treatment strategies for TD over the use of prophylactic antibiotics. Furthermore, they did not recommend doxycycline as an early treatment strategy. ${ }^{12}$

Doxycycline is still commonly used for malaria prophylaxis among international travelers. With changes in resistance patterns of enteric pathogens, it is unclear what effect doxycycline currently has on the development of TD. ${ }^{9-11}$ We examined a cohort of travelers who received various malariapreventive strategies, seeking to evaluate whether the use of doxycycline as malaria prophylaxis was associated with a decreased risk of TD during international travel.

\section{MATERIALS AND METHODS}

Study design. This study was a subset of the larger TravMil study: Deployment and Travel-Related Infectious Disease Risk Assessment, Outcomes, and Prevention Strategies among Department of Defense (DoD) Beneficiaries, approved by the Uniformed Services University of the Health Sciences Institutional Review Board (Bethesda, MD). TravMil is a prospective observational cohort of DoD beneficiaries traveling outside the continental United States for $\leq 6.5$ months. Consenting adults were enrolled pretravel at six military travel centers (Walter Reed National Military Medical Center, Bethesda, MD; Brooke Army Medical Center, San Antonio, TX; Naval Medical Center, Portsmouth, VA; Madigan Army Medical Center, Tacoma, WA; Naval Medical Center, San Diego, CA; and Landstuhl Regional Medical Center, Landstuhl, Germany) and in the pre-deployment setting between January 
2010 and August 2018. Eligible travelers were limited to DoD beneficiaries (e.g., active duty military personnel, military retirees, United States Public Health Service, Department of State employees, and military-dependent family members). Individuals were required to be traveling outside of the continental United States, Puerto Rico, Guam, Samoa, the U.S. Virgin Islands, western or northern Europe, Canada, or New Zealand for at least part of their itinerary. Military deployers were prescribed malaria prophylaxis in accordance with the military guidelines for their region of travel. Current DoD guidance recommends atovaquone-proguanil as the malaria prophylaxis for Africa. For all other regions, either doxycycline or atovaquone-proguanil can be prescribed at the discretion of their provider. Non-deployer travelers were prescribed malaria prophylaxis at the discretion of their provider.

Survey data. Pretravel enrollees completed a pretravel survey recording their demographic and travel characteristics. Prescriptions for malaria prophylaxis were abstracted from the clinic encounter. Travelers completed an illness diary during travel, recording the number of loose stools, abdominal pain, fever, nausea, and/or vomiting. Travelers' diarrhea was defined as three or more loose stools in a 24-hour period or two loose stools in a 24-hour period, and one or more of the following: nausea, vomiting, abdominal pain, fever, or bloody stool. Episodes of TD were analyzed for each registered trip. For each registered trip which could include multiple geographic regions, the traveler was prescribed doxycycline, other, or no malaria prophylaxis for the duration of that trip.

Statistical analysis. Univariate and multivariate analyses were performed to determine which trip and traveler characteristics, including use of malaria prophylaxis, were associated with the development of TD. For univariate and multivariate analyses, a Poisson regression with robust error variance was used to estimate the RR of our count data. $A$ robust error variance allowed for a tighter $\mathrm{Cl}$. Selected variables with a $P$-value of $<0.05$ on univariate analysis underwent a Poisson regression for multivariate analysis to assess independent risk factors. This allowed for exclusion of highly correlated covariate and mutually exclusive variables. Results of multivariate analysis were reported with the RR with $95 \%$ Cls. Statistical significance was defined as a $P$-value of $<0.05$. Statistical analysis was performed with SPSS software (IBM SPSS Statistics version 22, Chicago, IL).

\section{RESULTS}

Baseline characteristics. A total of 3,227 trips with 2,803 travelers were analyzed (Table 1). The majority of travelers were male $(62.1 \%)$, with a median age of 39 years (interquartile range $[\mathrm{IQR}] 27,59)$ and a median travel duration of 19 days (IQR $12,49)$. Caucasian $(70.7 \%)$ was the most commonly reported race. Twenty-five percent of travelers were aged $\geq 60$ years, and $27 \%$ who developed TD were aged $\geq 60$ years. For malaria prophylaxis, $20 \%$ were prescribed doxycycline, $50 \%$ prescribed another form of malaria prophylaxis $(89 \%$ of these were atovaquone-proguanil), and $30 \%$ were not prescribed malaria prophylaxis. Travelers' itineraries could include more than one region of travel. Forty-five percent traveled to Southeast (SE) Asia/Pacific Islands, 32\% traveled to Africa, and $2 \%$ traveled to tropical South America. The cumulative incidence of TD was $17 \%$, with an incidence rate of 53 per 1,000 travel days. Of the 406 trips where travelers developed TD and were prescribed malaria prophylaxis, the most common countries where TD occurred were Peru $(n=58,14.3 \%)$, Vietnam $(n=38,9.3 \%)$, India $(n=29,7.1 \%)$, and Honduras $(n=$ 28, 6.9\%).

More than one purpose of travel and multiple types of travel accommodations could be reported (Table 2). The most common purposes of travel were military (46\%) and vacation (40\%). Only $3 \%$ of travelers who traveled for military purposes were in non-active duty (representing government employees/ contractors). The most common travel accommodation was hotel $(71 \%)$.

Data on dietary habits were available for $70 \%$ of trips with military accommodations. On these trips, $8.6 \%$ of travelers dined in only military facilities, $24.5 \%$ dined in military and

TABLE 1

Traveler demographics, malaria prophylaxis prescribed, destinations, and incidence of TD

\begin{tabular}{|c|c|c|c|}
\hline Characteristic & All $(N=3,227)$ & Non-deployment travel $(N=2,154)$ & Deployment $(N=1,073)$ \\
\hline Gender, male, $n(\%)$ & $2,004(62)$ & $1,106(52)$ & $898(84)$ \\
\hline Median age (years) & $39($ IQR 27,59) & $51($ IQR 33,65) & 28 (IQR 23,35) \\
\hline Median duration of travel (days) & 19 (IQR 12,49) & 16 (IQR 11,27) & 34 (IQR 16,84) \\
\hline \multicolumn{4}{|l|}{ Race, $n(\%)$} \\
\hline African American & $345(11)$ & $244(11)$ & $101(9)$ \\
\hline Caucasian & $2,252(71)$ & $1,508(70)$ & 744 (69) \\
\hline \multicolumn{4}{|l|}{ Military status, $n(\%)$} \\
\hline Active duty & $1,658(51)$ & $585(27)$ & $1,073(100)$ \\
\hline Dependent & $1,454(45)$ & $1,454(68)$ & - \\
\hline \multicolumn{4}{|l|}{ Malaria prophylaxis prescribed, $n(\%)$} \\
\hline Doxycycline & $644(20)$ & $174(8)$ & $470(44)$ \\
\hline Other* & $1,623(50)$ & $1,235(57)$ & $388(36)$ \\
\hline None & 960 (30) & 745 (35) & 215 (20) \\
\hline \multicolumn{4}{|l|}{ Destinations, $n$ (\%) } \\
\hline Africa & $1,033(32)$ & $661(31)$ & $372(35)$ \\
\hline Southeast Asia/Pacific Islands & $1,255(39)$ & $774(36)$ & $481(45)$ \\
\hline $\begin{array}{l}\text { Caribbean, Mexico, and Central } \\
\text { America }\end{array}$ & $704(22)$ & $583(27)$ & $121(11)$ \\
\hline Tropical South America & $314(10)$ & $291(14)$ & $23(2)$ \\
\hline Multiple regions & $1,013(31)$ & $519(24)$ & $494(46)$ \\
\hline TD cumulative incidence, $n(\%)$ & $562(17)$ & $502(23)$ & $60(6)$ \\
\hline
\end{tabular}

travelers' diarrhea.

${ }^{\star} 89 \%$ atovaquone-proguanil. 
TABLE 2

Purpose of travel, travel accommodations, and type of travel location*

\begin{tabular}{lccc}
\hline Characteristic & All $(N=3,227), n(\%)$ & Non-deployment travel $(N=2,154), n(\%)$ & Deployment $(N=1,073), n(\%)$ \\
\hline Purpose of travel & & & \\
Military & $1,468(46)$ & $395(18)$ & $1,073(100)$ \\
Vacation & $1,282(40)$ & $1,282(40)$ & - \\
Missionary & $427(13)$ & $427(13)$ & - \\
$\quad$ Medical & $148(5)$ & $148(5)$ & - \\
Travel accommodations & $2,295(71)$ & $1,814(84)$ & $481(45)$ \\
$\quad$ Hotel & $879(27)$ & $181(8)$ & $698(65)$ \\
Dormitory & $198(6)$ & $198(6)$ & - \\
Military & $398(12)$ & $398(12)$ & - \\
Private & $1,752(54)$ & $1,036(48)$ & $716(67)$ \\
Type of location & $251(8)$ & $251(8)$ & - \\
$\quad$ Rural & Safari & &
\end{tabular}

outside facilities, and $66.9 \%$ dined in only outside facilities. There were 42 cases of TD within this group. There was one case of TD $(2.4 \%)$ in a traveler who ate only at military facilities versus $23.8 \%$ who ate at both military and outside facilities and $73.8 \%$ who ate at only outside facilities $(P=0.2)$.

Of those trips that required malaria prophylaxis $(n=2,267)$, self-reported compliance data were available for $84 \%$ of trips during the study period. Compliance was defined as completing all malaria prophylaxis during and after travel as prescribed. For travelers who were prescribed doxycycline $(n=$ 552), $70 \%$ reported compliance compared with $90 \%$ in the other malaria prophylaxis group $(P<0.01)$. Data on reasons for noncompliance were not collected.

Travelers' diarrhea association analysis. On univariate analysis of travel characteristics (Table 3), female travelers, travelers to tropical South America, and increased duration of travel were associated with increased risk of developing TD.
Vacation, missionary travel, hotel accommodations, and medical support missions were also associated with increased risk of developing TD. On univariate analysis, use of doxycycline for malaria prophylaxis (compared with combined group of use of other or no prophylaxis), travel to multiple regions, military purpose of travel, and dormitory accommodations were associated with decreased risk of TD. On univariate analysis, the RR of TD taking doxycycline for malaria prophylaxis versus another agent for malaria prophylaxis was 0.45 (0.35-0.58), $P<0.01$. The univariate RR of TD taking doxycycline versus no malaria prophylaxis was 0.59 (0.34-0.74), $P<0.01$. In addition to doxycycline, gender, military purpose of travel, travel to tropical South America, hotel accommodation, and duration of travel were chosen as variables for multivariate analysis. Gender and hotel accommodation were selected because they had a strong effect on the univariate analysis, and hotel accommodations represented a

TABLE 3

Univariate analysis of characteristics and RR of TD

\begin{tabular}{|c|c|c|c|c|}
\hline Characteristic & TD & No TD & Univariate RR (95\% Cl) & $P$-value \\
\hline \multicolumn{5}{|l|}{ Malaria prophylaxis, $n(\%)$} \\
\hline Doxycycline & $62(10)$ & $582(90)$ & $0.5(0.38-0.64)$ & $<0.01$ \\
\hline Other or none & $500(19)$ & $2,083(81)$ & Ref & - \\
\hline \multicolumn{5}{|l|}{ Gender, $n(\%)$} \\
\hline Male & $281(14)$ & $1,723(86)$ & Ref & - \\
\hline Female & $269(22)$ & $954(78)$ & $1.56(1.34-1.81)$ & $<0.01$ \\
\hline Age (years) & $44(30,62)$ & $38(26,58)$ & - & $<0.01$ \\
\hline Median duration of travel (days) & $19(13,34)$ & $9(12,43)$ & - & 0.61 \\
\hline \multicolumn{5}{|l|}{ Destinations, $n(\%)$} \\
\hline Africa & $180(17)$ & $853(83)$ & $1.00(0.85-1.18)$ & 0.99 \\
\hline Southeast Asia/Pacific Island & $207(17)$ & $1,048(83)$ & $0.92(0.78-1.07)$ & 0.27 \\
\hline Tropical South America & $81(26)$ & $233(74)$ & $1.48(1.21-1.82)$ & $<0.01$ \\
\hline Mexico/Caribbean/Central America & $132(19)$ & $572(81)$ & $1.06(0.88-1.28)$ & 0.49 \\
\hline Multiple regions & $131(13)$ & $882(87)$ & $0.66(0.55-0.80)$ & $<0.01$ \\
\hline \multicolumn{5}{|l|}{ Purpose of travel, $n(\%)$} \\
\hline Military & $168(11)$ & $1,300(89)$ & $0.51(0.43-0.60)$ & $<0.10$ \\
\hline Vacation & $279(22)$ & $1,003(78)$ & $1.50(1.28-1.74)$ & $<0.01$ \\
\hline Missionary & $117(27)$ & $310(73)$ & $1.72(1.44-2.06)$ & $<0.01$ \\
\hline Medical & 47 (32) & $101(68)$ & $1.9(1.48-2.43)$ & $<0.01$ \\
\hline \multicolumn{5}{|l|}{ Travel accommodations, $n(\%)$} \\
\hline Hotel & $469(20)$ & $1,826(80)$ & $1.43(1.22-1.68)$ & $<0.01$ \\
\hline Dormitory & $88(10)$ & $791(90)$ & $0.50(0.40-0.61)$ & $<0.01$ \\
\hline Military & $54(27)$ & 144 (73) & $1.62(1.28-2.06)$ & $<0.01$ \\
\hline Private & $128(22)$ & $458(78)$ & $1.32(1.12-1.58)$ & $<0.01$ \\
\hline \multicolumn{5}{|l|}{ Type of location, $n(\%)$} \\
\hline Rural & $291(17)$ & $1,461(83)$ & $0.92(0.78-1.05)$ & 0.18 \\
\hline Safari & $60(24)$ & $191(76)$ & $1.42(1.12-1.79)$ & $<0.01$ \\
\hline
\end{tabular}

TD = travelers' diarrhea 
large proportion of the study population. Military purpose of travel was chosen as this is one of the key populations in the TravMil group and to ensure that doxycycline use and military travel were both considered in the model simultaneously. Travel to tropical South America was chosen for multivariate analysis as it was a distinct geographic region that was significantly associated with TD on univariate analysis. On multivariate analysis (Table 4), use of doxycycline (0.62 [0.47-0.82], $P<0.01)$ and military purpose of travel $(0.57$ [0.47-0.7], $P<0.01)$ remained significantly associated with decreased risk. On multivariate analysis (1.28 [1.09-1.5], $P<0.01)$, the median duration of travel (days) (1.0 [1.0-1.01], $P<0.01)$, travel to tropical South America (1.34 [1.09-1.64], $P<0.01)$, and hotel accommodations (1.3 [1.1-1.53], $P<0.01)$ were associated with increased risk.

A further analysis of the use of doxycycline by region and associations with TD was performed. In our study, the region with the highest overall TD rates was Latin America at $20 \%$. When this group was further subdivided into tropical South America, and the overall TD rate was $25 \%$. There were similar rates of TD in Africa and Asia at $17 \%$ and $16 \%$, respectively. When Asia was further subdivided into SE Asia, the TD rate was $13 \%$. There was a decreased RR of TD when taking doxycycline and traveling to Latin America (0.85 [0.8-0.91], $P=0.01)$ and SE Asia (0.89 [0.85-0.94], $P<0.01)$. However, there was no statistically significant decreased RR of TD in the doxycycline groups in travelers to Africa and tropical South America, possibly secondary to the limited number of travelers on doxycycline in these groups $(N=75$ and $N=13)$.

Military subgroup analysis. Because $82 \%$ of the doxycycline group were traveling for a military purpose, a subgroup analysis was performed (Table 5). A multivariate Poisson performed with the same variables as earlier, with the exception of travel to tropical South America because of the limited number of military travelers visiting this destination showed that doxycycline continued to have a statistically significant decreased RR of TD (0.46 [0.32-0.66], $P<0.01)$. Female gender (1.69 [1.25-2.3], $P<0.01)$, hotel accommodations (1.62 [1.25-2.3], $P<0.01$ ), and longer duration of travel (1.01 [1.00-1.01], $P<0.01)$ continued to have a statistically significant increased RR of TD.

\section{DISCUSSION}

Our evaluation of the use of doxycycline as malaria prophylaxis and risk of TD among international travelers demonstrates a negative association between doxycycline used as malaria prophylaxis and incidence of TD in international travelers. Given the widespread prevalence of TD in international travelers, as well as the limitations and unclear

TABLE 4

Multivariate analysis of characteristics and their RR of travelers' diarrhea

\begin{tabular}{lcc}
\hline \multicolumn{1}{c}{ Characteristic } & Multivariate RR $(95 \% \mathrm{Cl})$ & Multivariate $P$-value \\
\hline Doxycycline use & $0.62(0.47-0.82)$ & $<0.01$ \\
Female gender & $1.28(1.09-1.5)$ & $<0.01$ \\
Median duration of travel (days) & $1.0(1.0-1.01)$ & $<0.01$ \\
Tropical South America & $1.34(1.09-1.64)$ & $<0.01$ \\
Military travel & $0.57(0.47-0.7)$ & $<0.01$ \\
Hotel accommodations & $1.30(1.1-1.53)$ & $<0.01$ \\
\hline
\end{tabular}

TABLE 5

Multivariate analysis of characteristics and their RR of travelers' diarrhea in military subgroup

\begin{tabular}{lcc}
\hline \multicolumn{1}{c}{ Characteristic $(N=1,468)$} & Multivariate $\mathrm{RR}(95 \% \mathrm{Cl})$ & Multivariate $P$-value \\
\hline Doxycycline use & $0.46(0.32-0.66)$ & $<0.01$ \\
Female gender & $1.69(1.25-2.29)$ & $<0.01$ \\
Median duration of travel (days) & $1.01(1.0-1.01)$ & $<0.01$ \\
Hotel accommodations & $1.62(1.19-2.22)$ & $<0.01$ \\
\hline
\end{tabular}

efficacy of dietary restrictions for prevention, and limited options for chemoprophylaxis, these findings warrant consideration. Rifaximin is approved for the prevention of TD in selected populations. ${ }^{5}$ Meta-analysis shows that rifaximin has a decreased RR of developing TD (RR 0.41 [0.3-0.56], $P<$ $0.01)^{13}$ compared with our study showing doxycycline RR of 0.62 (0.47-0.82), $P<0.01$. Although these observational data do not derive from a randomized controlled trial, the findings support doxycycline effectiveness in TD prevention.

Identification of the precise etiologic agent of TD has historically been difficult. With advances in etiologic determination using molecular-based diagnostics, there is increased capability to identify the causative agent of TD. ${ }^{14,15}$ Even with these advances in technology, studies still show that $25-30 \%$ of samples will have no pathogen identified. ${ }^{3,16}$ When a pathogen is identified, diarrheagenic $E$. coli (DEC), primarily ETEC and EAEC, are the most common etiologies globally with some regional variation where other agents are identified, such as in Southeast Asia where Campylobacter is common. ${ }^{16}$ Other TD bacterial pathogens of concern such as Shigella, Salmonella, and non-cholera Vibrio species only represent $<10 \%$ of TD globally. 3,16

Doxycycline use as a prophylactic antibiotic against TD pathogens, especially DEC, has been well documented historically. In 1976 and 1977, randomized double-blinded placebo-controlled trials in Peace Corps volunteers in Kenya and Morocco showed that a 100-mg daily dose (malaria prophylaxis dose) of doxycycline offered $83-86 \%$ protection against TD. ${ }^{7,8}$ In 1980, another randomized double-blinded placebo-controlled trial in Peace Corps volunteers in Thailand using the 100-mg daily dose of doxycycline did not show statistically significant protection from TD. ${ }^{10}$ Similar studies in 1980 and 1981 in Honduras and Mexico did show a statistically significant protective effect of doxycycline against TD, respectively. ${ }^{11,17}$ Notably, in those studies that showed a protective effect of doxycycline, most stools of symptomatic participants grew ETEC. $7,8,11,17$ The Honduras study which showed the lowest level of statistically significant protection with doxycycline (68\% versus $80 \%$ in all other studies) also showed $54 \%$ of the ETEC isolates in the doxycycline group were resistant to doxycycline. Interestingly, the subjects that developed TD while on doxycycline and grew doxycyclineresistant ETEC had less severe symptoms than subjects with TD in the placebo group. ${ }^{11}$ These studies show the historic microbiologic basis for doxycycline having a protective effect against TD.

To further explore the decreased risk of TD seen with doxycycline in our study, it is important to review the evolution of doxycycline resistance. In 1983, the $\mathrm{MIC}_{90}$ of doxycycline against Salmonella was $64 \mu \mathrm{g} / \mathrm{mL}$, Shigella $16 \mu \mathrm{g} / \mathrm{mL}$, Campylobacter $8 \mu \mathrm{g} / \mathrm{mL}$, and ETEC $32 \mu \mathrm{g} / \mathrm{mL}^{18}$ Given these $\mathrm{MIC}_{90 \mathrm{~s}}$, doxycycline's long half-life, and high intraluminal 
concentration, doxycycline was still considered to be an efficacious prophylactic medication for TD. By 1997, there was an increase in the $\mathrm{MIC}_{90 \text { s }}$ of all of these enteric pathogens against doxycycline. The $\mathrm{MIC}_{90}$ of doxycycline against Salmonella and Shigella was now 128, ETEC 64, and Campylobacter 64. In addition, this 1997 study showed regional differences in antibiotic susceptibility. ${ }^{19}$ This study showed the increasing levels of doxycycline resistance and that prophylactic use of doxycycline may only be efficacious against certain pathogens in distinct parts of the world. A more recent study looked at the resistance patterns of ETEC in Bangladesh over time. From 2005 to 2009, the prevalence of doxycycline resistance among ETEC isolates increased from $33 \%$ to $44 \%$. $^{15}$

Among common causes of TD, ETEC remains the pathogen with the highest likelihood of susceptibility to doxycycline. Notably, there is not an even geographic distribution of ETEC. According to the Global Burden of Disease Study 1990-2016, the global burden of ETEC is approximately 30.1 cases per 1,000 person years. Of note, one of the highest regions of ETEC incidence was Andean Latin America (Bolivia, Peru, and Ecuador) at 81.1 cases per 1,000. The Global Burden of Disease Study also shows that for high TD incidence regions, Southeast Asia has lower incidence of ETEC $(30.8 / 1,000)$ than other high-burden regions such as sub-Saharan Africa (52.8/ 1,000). ${ }^{20}$ In our study, a known region with a high ETEC burden, Latin America, was shown to have a statistically significant decreased RR of TD for travelers on doxycycline $(0.85$ [0.8-0.9.91], $P=0.01$ ). The region of tropical South America which includes Andean Latin America did not show a statistically significant decreased RR of TD on doxycycline $(0.87$ [0.69-1.110], $P=0.53$ ), which may be secondary to the limited amount of travelers on doxycycline. A recent analysis from the same TravMil cohort used TaqMan Array Card testing of selfcollected stool smears on Whatman FTA Elute Cards to determine the pathogen-specific epidemiology of TD and found ETEC to be the most commonly associated pathogen and in similar proportions across geographic areas of the world. ${ }^{21}$ The reasons for differing the RR of TD in travelers using doxycycline in our study could include differing rates of ETEC, differing rates of doxycycline resistance, or limited statistical power for certain regions.

Nonmicrobial effects of doxycycline may also contribute to a decreased risk of TD. Diarrhea is a highly inflammatory process. Murine models have shown that T-cell activation of tumor necrosis factor (TNF), interleukin (IL)-1, IL-6, and other cytokines induces fluid accumulation in the small bowel, leading to diarrhea. ${ }^{22}$ In addition, studies in children have shown high serum levels of TNF- $\alpha$, IL-6, and IL-10 after having viral and/or bacterial gastroenteritis. ${ }^{23,24}$ Tetracyclines have a regulatory influence on the immune system and inflammatory pathways. ${ }^{25,26}$ Doxycycline has been shown to inhibit activation of macrophages which in turn inhibits TNF- $\alpha$, IL-1b, IL-6, and other proinflammatory proteins. Tetracyclines also inhibit lipopolysaccharide-induced nitric oxide production. Nitric oxide production has been implicated in the pathophysiology of sepsis. ${ }^{25}$ Doxycycline also has antioxidant properties, thereby reducing tissue destruction. ${ }^{27}$ Therefore, the decreased $R R$ of TD seen in our study could be theoretically related to doxycycline, reducing the inflammatory cascade associated with diarrhea independent of direct antimicrobial effects.

Several additional factors described in this study as being associated with risks of TD are consistent with previously published data. Latin America has been well established as a high-risk TD incidence region, with attack rates approximating 39.4 cases per 100 person-months. ${ }^{28-30}$ Associations with gender and development of TD have been previously reported. ${ }^{3,31}$ GeoSentinel data have shown that females have a higher rate of developing acute diarrhea, chronic diarrhea, and IBS. ${ }^{31}$ Although other studies have not shown difference in rates of TD, they found that females are more likely to seek medical care for their TD. ${ }^{3}$

Interestingly, hotel stay has been previously reported as being associated with increased risk of TD. ${ }^{3,32}$ Some associations between hotel stay and TD have been secondary to an outbreak. ${ }^{32}$ However, Steffen et al. ${ }^{3}$ showed that hotel stay in high-risk geographic regions for TD was associated with increased risk of TD. In addition, this study showed that allinclusive resorts had an overall higher rate of TD than when participants had to pay for meals at their hotel. ${ }^{32}$ Although our study did show an increased RR of TD in subjects staying at a hotel, it is unknown how many participants stay in all-inclusive resorts in our study.

Our study had multiple limitations. First, our study collected observational data with self-reported enteric symptoms as well as adherence to malaria prophylaxis. The lack of TD pathogen identification limits a direct assessment of doxycycline breakthroughs. Our study did not record confounding medical conditions or concomitant medications that could predispose travelers TD or influence providers' decision on which malaria prophylaxis to prescribe. Dietary habits and the risk for TD were not explored in non-deployment travel portion of this study as previous TravMil studies have not shown an association between TD and dietary habits. ${ }^{33}$ Finally, although we attempted to control for geographic variability to some extent in the multivariate analysis, it may be that areas of travel in which prescribers favored doxycycline also may be lowerrisk itineraries with lower rates of TD.

Previous studies have shown that there is seasonality in TD. Season affects both the frequency of TD seen and pathogens causing TD. ${ }^{34}$ In our study, the median travel duration was 19 days. However, on military deployment trips, the median duration was 34 days. In addition, subjects frequently traveled to multiple locations, 31\%, and, therefore, portions of their travel could be in different regions of exposure. Because so many trips involved changes in season (including changes in seasonality based on geography), we did not explore seasons of travel and their effect on TD.

Because the aim of the study was to look at the risk factors associated with TD, the use of antibiotics for TD self-treatment was not addressed in this study. In addition, this study was designed to show the effect of doxycycline as malaria prophylaxis on TD during an acute period of time. One of the limitations of this study is that long-term effects of the use of doxycycline were not evaluated. TravMil is currently evaluating risk factors for extended B-lactamase (ESBL) E. coli colonization after military travel by looking at region of travel, malaria prophylaxis, and antibiotics used for TD selftreatment. Initial data from this study did not show the use of doxycycline as malaria prophylaxis or the use of antibiotics for self-treatment of TD to be associated with ESBL colonization. ${ }^{35}$ Studies in civilian populations have shown association between antibiotic use for self-treatment of TD and ESBL colonization. ${ }^{36,37}$ However, when one study looked at antibiotics used for reasons other than self-treatment of TD and 
antimalarial chemoprophylaxis, there was no association with ESBL colonization. ${ }^{36}$

Doxycycline for malaria prophylaxis requires an additional 28 days of medication after returning from travel. These long courses of antibiotics also have the potential to alter the microbiome and cause antibiotic induce Clostridioides difficile. There are mixed data on the correlation between doxycycline and $C$. difficile. This case-controlled study of hospitalized patients studied the relationship between certain antibiotics and hospital-acquired $C$. difficile infection (CDI). Doxycycline had a slightly reduced risk of CDI with an odds ratio of $0.41 .^{38}$ However, there have been case series of travelers taking doxycycline for malaria prophylaxis developing $\mathrm{CDI} .{ }^{39}$ With doxycycline's ability to highly concentrate in the bowel, there is concern for this antibiotic altering the gastrointestinal microbiome. ${ }^{40}$ Studies of subjects taking long courses of doxycycline (more than 1 year in these studies) have shown decreased diversity in the gastrointestinal microbiome. ${ }^{41,42}$

One of the greatest strengths of our study is the large sample size, with 3,227 trips recorded including various approaches to malaria prophylaxis, which allowed for comparison of doxycycline TD prophylaxis effectiveness. Furthermore, our military subgroup analysis showed that the use of doxycycline was still associated with a statistically significant decrease in TD risk, further strengthening our findings and decreasing the likelihood that the decreased risk may be attributed to some other militaryspecific aspect of travel.

\section{CONCLUSION}

The cumulative incidence of TD in international travelers who were taking doxycycline for malaria prophylaxis was decreased compared with those taking other or no prophylaxis. This effect may be because of increasing bacterial enteropathogen susceptibility to doxycycline against diarrheagenic $E$. coli, similar to observations from over 30 years ago, and potential anti-inflammatory effects. Further prospective studies should be performed to establish if there are any additional benefits of using doxycycline as malaria prophylaxis.

Received April 3, 2020. Accepted for publication July 11, 2020.

Published online August 17, 2020.

Acknowledgments: We thank the Infectious Disease Clinical Research Program TravMil study team of clinical coordinators, laboratory technicians, data managers, clinical site managers, and administrative support personnel for their contributions to this project.

Financial support: This study (IDCRP-037) was supported by the Infectious Disease Clinical Research Program (IDCRP), a Department of Defense (DoD) program executed by the Uniformed Services University of the Health Sciences (USUHS) through a cooperative agreement with the Henry M. Jackson Foundation for the Advancement of Military Medicine, Inc. (HJF). This project has been funded in whole, or in part, with federal funds from the National Institute of Allergy and Infectious Diseases, National Institutes of Health $(\mathrm{NIH})$, under Inter-Agency Agreement Y1-Al-5072, and from the Department of Defense Global Emerging Infections Surveillance.

Copyright statement: Some authors are service members of the U.S. Government. This work was prepared as part of their official duties. Title 17 U.S.C. $\$ 105$ provides that "Copyright protection under this title is not available for any work of the United States Government." Title 17 U.S.C. $\$ 101$ defines a U.S. Government work as a work prepared by a military service member or employee of the U.S. Government as part of that person's official duties.

Disclaimer: The contents of this publication are the sole responsibility of the author(s) and do not necessarily reflect the views, opinions, or policies of Uniformed Services University of the Health Sciences (USUHS), the Department of Defense (DoD), the Department of the Army, the Department of the Navy, or the Department of the Air Force, or Brooke Army Medical Center, the U.S. Army Medical Department, the U.S. Army Office of the Surgeon General, Landstuhl Regional Medical Center, Walter Reed National Military Medical Center, Madigan Army Medical Center, Naval Medical Center Portsmouth, or the Henry M. Jackson Foundation for the Advancement of Military Medicine, Inc. The views expressed in this article are those of the author(s) and do not reflect the official policy or position of the Department of the Army, the Department of Defense, or the U.S. government. Mention of trade names, commercial products, or organizations does not imply endorsement by the U.S. government.

Disclosure: The investigators have adhered to the policies for the protection of human subjects as prescribed in 45 CFR 46.

Authors' addresses: Kathryn Lago and Heather C. Yun, Brooke Army Medical Center, Fort Sam Houston, TX, and Uniformed Services University of the Health Sciences, Bethesda, MD, E-mails: kathryn.j.lago.mil@mail.mil and heather.c.yun.mil@mail.mil. Kalyani Telu, Jamie Fraser, and Indrani Mitra, Infectious Disease Clinical Research Program, Department of Preventive Medicine and Biostatistics, Uniformed Services University of the Health Sciences, Bethesda, MD, and The Henry M. Jackson Foundation for the Advancement of Military Medicine, Inc., Bethesda, MD, E-mails: ktelu@ idcrp.org, jamie.fraser.ctr@usuhs.edu, and imitra@idcrp.org. David Tribble, Infectious Disease Clinical Research Program, Department of Preventive Medicine and Biostatistics, Uniformed Services University of the Health Sciences, Bethesda, MD, E-mail: david.r.tribble.civ@ mail.mil. Anuradha Ganesan, Infectious Disease Clinical Research Program, Department of Preventive Medicine and Biostatistics, Uniformed Services University of the Health Sciences, Bethesda, MD, The Henry M. Jackson Foundation for the Advancement of Military Medicine, Inc., Bethesda, MD, and Walter Reed National Military Medical Center, Bethesda, MD, E-mail: anuradha.ganesan.ctr@mail.mil. Anjali Kunz, Madigan Army Medical Center, Tacoma, WA, E-mail: anjali.n.kunz.mil@mail.mil. Charla Geist, Landstuhl Regional Medical Center, Landstuhl, Germany, E-mail: charla.c.geist.mil@mail.mil. Tahaniyat Lalani, Infectious Disease Clinical Research Program, Department of Preventive Medicine and Biostatistics, Uniformed Services University of the Health Sciences, Bethesda, MD, The Henry M. Jackson Foundation for the Advancement of Military Medicine, Inc., Bethesda, MD, and Naval Medical Center, Portsmouth, VA, E-mail: tlalani@idcrp.org.

This is an open-access article distributed under the terms of the Creative Commons Attribution (CC-BY) License, which permits unrestricted use, distribution, and reproduction in any medium, provided the original author and source are credited.

\section{REFERENCES}

1. Hill DR, Beeching NJ, 2010. Travelers' diarrhea. Curr Opin Infect Dis 23: $481-487$.

2. Leder K et al., 2013. GeoSentinel surveillance of illness in returned travelers, 2007-2011. Ann Intern Med 158: 456-468.

3. Steffen R, Hill DR, DuPont HL, 2015. Traveler's diarrhea: a clinical review. JAMA 313: 71-80.

4. Schwille-Kiuntke J, Mazurak N, Enck P, 2015. Systematic review with meta-analysis: post-infectious irritable bowel syndrome after travellers' diarrhoea. Aliment Pharmacol Ther 41: 10291037.

5. Riddle MS et al., 2017. Guidelines for the prevention and treatment of travelers' diarrhea; a graded expert panel report. J Travel Med 24: S63-S80.

6. Riddle MS, Martin GJ, Murray CK, Burgess TH, Connor P, Mancuso JD, Schnaubelt ER, Ballard TP, Fraser J, Tribble DR, 2017. Management of acute diarrheal illness during deployment: a deployment health guideline and expert panel report. Mil Med 182: 34-52. 
7. Sack RB, Kaminsky DC, Sack RB, Itotia JN, Arthur RR, Kapikian AZ, Orskov F, 1978. Prophylactic doxycycline for travelers' diarrhea. Results of a prospective double-blinded study of Peace Corp volunteers in Kenya. N Engl J Med 298: 758-763.

8. Sack RB, Froehlich JL, Zulich AW, Hidi DS, Kapikian AZ, Orskov F, Greenberg HB, 1979. Prophylactic doxycycline for travelers' diarrhea. Results of a prospective double-blinded study of Peace Corp volunteers in Morocco. Gastroenterology 76: 1366-1373.

9. Qadri F, Svennerholm AM, Faruque AS, Sack RB, 2005. Enterotoxigenic Escherichia coli in developing countries: epidemiology, microbiology, clinical features, treatment, and prevention. Clin Microbiol Rev 18: 465-483.

10. Echeverria P, Pitarangsi C, Eampokalap B, Vibulbandhitkit S, Boonthai $P$, Rowe $B, 1983$. A longitudinal study of the prevalence of bacterial enteric pathogens among adults with diarrhea in Bangkok, Thailand. Diagn Microbiol Infect Dis 1: 193-204.

11. Sack RB, Santosham M, Froehlich JL, Medina C, Orksov F, Orksov I, 1984. Doxycycline prophylaxis of traveler's diarrhea in Honduras, an area where resistance to doxycycline is common among enterotoxigenic Escherichia coli. Am J Trop Med Hyg 33: $460-467$.

12. Gorbach SL et al., 1985. Traveler's diarrhea. NIH consensus development conference. JAMA 253: 2700-2704.

13. Hu Y, Ren J, Zhan M, Li W, Dai H, 2012. Efficacy of rifaximin in prevention of travelers' diarrhea: a meta-analysis of randomized, double-blind, placebo-controlled trials. J Travel Med 19: 352-356.

14. Buss SN, Leber A, Chapin K, Fey PD, Bankowski MJ, Jones MK, Rogatcheva M, Kanack KJ, Bourzac KM, 2015. Multicenter evaluation of the BioFire FilmArray gastrointestinal panel for etiologic diagnosis of infectious gastroenteritis. J Clin Microbiol 53: 915-925.

15. Begum YA, Talukder KA, Azmi IJ, Shahnaij M, Sheikh A, Sharmin S, Svennerholm AM, Qadri F, 2016. Resistance pattern and molecular characterization of enterotoxigenic Eschericial coli (ETEC) strains isolated in Bangladesh. PLoS One 11: e0157415.

16. Shah N, DuPont HL, Ramsey DJ, 2009. Global etiology of travelers' diarrhea; systematic review from 1973 to the present. Am $J$ Trop Med Hyg 80: 609-615.

17. Freeman LD, Hooper DR, Lathen DF, Nelson DP, Harrison WO, Anderson DS, 1983. Brief prophylaxis with doxycycline for the prevention of traveler's diarrhea. Gastroenterology 84: 276-281.

18. Carlson JR, Thornton SA, DuPont HL, Hanna West A, Mathewson JJ, 1983. Comparative in vitro activities of ten antimicrobial agents against bacterial enteropathogens. Antimicrob Agents Chemother 24: 509-513.

19. Gomi H, Jiang ZD, Adachi JA, Ashley D, Lowe B, Verenkar MP, Steffen R, DuPont HL, 2001. In vitro antimicrobial susceptibility testing of bacterial enteropathogens causing traveler's diarrhea in four geographic regions. Antimicrob Agents Chemother 45: 212-216.

20. Khalil IA et al., 2018. Morbidity and mortality due to shigella and enterotoxigenic Escherichia coli diarrhea: the global burden of disease study 1990-2016. Lancet Infect Dis 18: 1229-1240.

21. Tisdale M et al., 2019. A Quantitative Analysis Using TaqMan Array Card Testing of Self-Collected Stool Smears on Whatman FTA Elute Cards to Determine the Pathogen Specific Epidemiology of Travelers' Diarrhea. Presented at the 68th Annual Meeting of the American Society of Tropical Medicine and Hygiene, November 21, 2019, National Harbor, MD.

22. Musch MW et al., 2002. T cell activation causes diarrhea by increasing intestinal permeability and inhibiting epithelial $\mathrm{Na}^{+} / \mathrm{K}^{+}-$ ATPase. J Clin Invest 110: 1739-1747.
23. Hsu TR, Chen SJ, Wu TZ, Chung RL, Tang RB, 2005. Tumor necrosis factor-alpha and interleukin-10 in viral and bacterial gastroenteritis in children. J Chin Med Assoc 68: 250-254.

24. Kutukculer N, Caglayan S, 1997. Tumor necrosis factor-alpha and interleukin- 6 in stools of children with bacterial and viral gastroenteritis. J Pediatr Gastroenterol Nutr 25: 556-557.

25. Dunston CR, Griffiths HR, Lambert PA, Staddon S, Vernallis AB, 2011. Proteomic analysis of the anti-inflammatory action of minocycline. Proteomics 11: 42-51.

26. Di Caprio R, Lembo S, Di Costanzo L, Balato A, Monfrecola G, 2015. Anti-inflammatory properties of low and high doxycycline doses: an in vitro study. Mediators Inflamm 2015: 329418.

27. Bahrami F, Morris DL, Pourgholami MH, 2012. Tetracyclines: drugs with huge therapeutic potential. Mini Rev Med Chem 12: 44-52.

28. Olson S, Hall A, Riddle MS, Porter CK, 2019. Travelers' diarrhea: update on the incidence, etiology and risk in military and similar populations-1990-2005 versus 2005-2015, does a decade make a difference? Trop Dis Travel Med Vaccines 5: 1.

29. Hill DR, 2000. Health problems in a large cohort of Americans traveling to developing countries. J Travel Med 7: 259-266.

30. Diemert DJ, 2006. Prevention and self-treatment of traveler's diarrhea. Clin Microbiol Rev 19: 583-594.

31. Schlagenhauf $P$ et al., 2010. Sex and gender differences in travelassociated disease. Clin Infect Dis 50: 826-832.

32. Hardie RM, Wall PG, Gott P, Bardhan M, Bartlett CLR, 1999. Infectious diarrhea in tourists staying in a resort hotel. Emerg Infect Dis 5: 168-171.

33. Lalani T et al.; IDCRP TravMil Study Group, 2015. Epidemiology and self-treatment of travelers' diarrhea in a large, prospective cohort of department of defense beneficiaries. J Travel Med 22: 152-160.

34. Mattila L et al., 1995. Risk behavior for travelers' diarrhea among Finnish travelers. J Travel Med 2: 77-84.

35. Buchek G et al., 2018. Travel-Associated Multidrug-Resistant Organism Acquisition and Risk Factors among US Military Personnel. Presented at the ID Week 2018, October 5, 2018, San Francisco, CA.

36. Kantele A, Lääveri T, Mero S, Vilkman K, Pakkanen SH, Ollgren J, Antikainen J, Kirveskari J, 2015. Antimicrobials increase travelers' risk of colonization by extended-spectrum betalactamaseproducing enterobacteriaceae. Clin Infect Dis 60: 837-846.

37. Kennedy K, Collignon P, 2010. Colonisation with Escherichia coli resistant to "critically important" antibiotics: a high risk for international travellers. Eur J Clin Microbiol Infect Dis 29: 1501-1506.

38. Baxter R, Ray G, Fireman B, 2008. Case-control study of antibiotic use and subsequent Clostridium difficile-associated diarrhea in hospitalized patients. Infect Control Hosp Epidemiol 29: 44-50.

39. Golledge CL, Riley TV, 1995. Clostridium difficile-associated diarrhoea after doxycycline malaria prophylaxis. Lancet 345: 1377-1378.

40. Hung YP, Lee JC, Lin HJ, Liu HC, Wu YH, Tsai PJ, Ko WC, 2015. Doxycycline and tigecycline: two friendly drugs with a low association with Clostridium difficile infection. Antibiotics 4: 216-229.

41. Haas $\mathrm{K}$ et al., 2018. Doxycycline Effects on the Gut and Skin Microbiomes and Lipidome in Acne. Presented at the 2018 Annual Meeting for International Investigative Dermatology, May 17, 2018, Orlando, FL.

42. Angelakis E, Million M, Kankoe S, Lagier JC, Armougom F, Giorgi $\mathrm{R}$, Raoult D, 2014. Abnormal weight gain and gut microbiota modifications are side effects of long-term doxycycline and hydroxychloroquine treatment. Antimicrob Agents Chemother 58: 3342-3347. 